\title{
O estudo da prática cosplay e os métodos da História Oral: protocolos e rupturas em uma cena jovem
}

Study of Cosplay PRACtice and Oral History methods: PROTOCOLS AND RUPTURES IN A YOUTH SCENE

\section{Mônica Rebecca Ferrari Nunes}

Docente e pesquisadora do PPGCOM-ESPM. Doutora em Comunicação e Semiótica (PUCSP).

E-mail: monicarfnunes@espm.br

\section{Resumo}

Este artigo integra o Projeto de Pesquisa Comunicação, consumo e memória: cosplay e culturas juvenis (CNPq/ESPM). O trabalho relata os processos da pesquisa e os métodos da História Oral utilizados no trabalho de campo em treze eventos de animês localizados na região Sudeste do Brasil de modo a cartografar regularidades e singularidades na prática cosplay, em que jovens se vestem como personagens de narrativas midiáticas. A história temática e histórias de vida configuraram painel significativo da cena: das motivações às relações entre memória e consumo das narrativas representadas pelo cosplayer.

Palavras-chave: Cosplay; História Oral; Cena Jovem.

\section{Abstract}

This paper is part of a broader study named “Comunicação, consumo e memória: cosplay e culturas juvenis" (CNPq/ESPM). It reports the researching processes and Oral History methods used in the fieldwork of thirteen anime events carried out in the Southeast region of Brazil, to map regularities and singularities of the cosplay practice, showing youth dressing up as media narrative characters. Thematic history and life histories form a significant cross-section of the scene: from motivations to connections between memory and consumption of the narratives represented by cosplayers.

Key words: Cosplay; Oral History; Youth Scene 


\section{Introdução}

Nunca é demais saudar a diversidade de aportes teóricos e de metodologias que compõem o campo da Comunicação, lugar de misturas sígnicas, trânsitos de linguagens e textos culturais, para usar a terminologia semiótica da cultura de Tártu-Moscou (LOTMAN, 1996). A Comunicação é uma ciência interdisciplinar e, nesta medida, pode absorver metodologias e técnicas relacionadas a outras disciplinas, a exemplo da utilização da História Oral para o estudo de objetos da Comunicação.

O esforço para definir o objeto da Comunicação ou quais são os seus objetos de pesquisa nos conduz à compreensão dos próprios processos comunicativos. Acompanhados por Harry Pross, podemos entender melhor a complexidade destes engendramentos. O cientista político e da comunicação alemão, citado por Baitello Junior (2010), ensina que a comunicação pode ser pensada como processos de mediação. Assim, a comunicação ou mediação primária se refere ao corpo em presença, que responde pela produção de sentido com seus gestos, sons, cheiros, paladares, comportamentos. Aqui o corpo é mídia primária; quando os corpos deixam sobre outros suportes suas marcas, como inscrições, imagens, escritas em variados suportes, inclusive sobre o próprio corpo, como tatuagens, e toda a sorte de adereços, estas marcas expandem o corpo-mídia no tempo e no espaço e inauguram a comunicação ou mediação secundária. Já a comunicação terciária acontece com a chegada da eletricidade e a presença dos aparatos eletromagnéticos, como o cinema, o rádio, a televisão, os computadores. Precisamos de aparatos eletromagnéticos ou digitais para decodificar as mensagens produzidas por outros equipamentos. Vale esclarecer que estes processos se interpenetram, "há aí uma cumulatividade na passagem da primária para a secundária e da secundária para terciária, a secundária contém a primária e a terciária contém a secundária e a primária" (BAITELLO JUNIOR, 2010, p. 63).

Baitello Junior ainda adverte que, de modo algum, esta classificação significa que a comunicação primária é menos complexa do que as outras e de que a terciária seja mais importante. "Cada uma delas possui vantagens e desvantagens, seu potencial maior ou menor, sua melhor ou menos adequada aplicabilidade para cada determinada situação". O instigante é que "sempre há um corpo no início e no final de todo processo de comunicação, afirma Harry Pross" (BAITELLO JUNIOR, 2010. Ibid.).

O corpo, suas mediações, - nesta medida, considerando igualmente suas transformações - manifestações e processos comunicacionais gerados constituem objetos da Comunicação. Diante deles, a História Oral se apresenta como um relevante instrumento metodológico, técnico e como fonte de pesquisa. Ainda que seja "um ponto de confluência disciplinar" (LANG, 2013, p. 78), ou "um método que sempre foi essencialmente 
interdisciplinar, um caminho cruzado entre sociólogos, antropólogos, historiadores, estudantes de literatura e cultura, e assim por diante" (THOMPSON, 2002, p. 10), a História Oral tem suas especificidades. Uma delas é a utilização das fontes orais, materializadas em entrevistas e depoimentos, de sorte a produzir narrativas, por sua vez, tão caras às abordagens que não descolam os processos da comunicação das ciências da cultura e cultura de memória. Estas conexões definem meu lugar de fala.

Com base no relato da pesquisa "Comunicação, consumo e memória: cosplay e culturas juvenis" (PPGCOMESPM/CNPq) ${ }^{1}$, em fase de finalização, coordenada por mim e levada a termo pelos membros² da linha de pesquisa em Comunicação, consumo e memória, vinculada ao grupo de pesquisa "Comunicação, consumo e entretenimento" (PPGCOM-ESPM/diretórios de GP do CNPq), este artigo objetiva descrever e refletir sobre os usos dos métodos da História Oral que foram incorporados ao trabalho, evidenciando os impasses e alcances obtidos pela pesquisa.

Inicialmente, discute-se a importância do corpo-mídia e das narrativas que este corpo produz; a seguir, o artigo ressalta a força simbólica da palavra que nomeia e traz à vida o que estava soterrado e como palavra e narrativa atravessam a história da memória alcançando os princípios da História Oral. Na sequência, há a descrição do projeto em pauta e por fim o relato dos métodos aplicados à pesquisa.

\section{Corpo-mídia e suas narrativas}

O paleontólogo e antropólogo francês, Leroi-Gourhan (1985), em um texto clássico produzido durante os anos sessenta, discorre, ao longo de dois volumes, sobre as relações intrínsecas entre o gesto arcaico de fabrico de utensílios, da criação da arte rupestre e parietal e a palavra. Gourhan destaca que o gesto e a palavra que narra estão conectados rumo ao desenvolvimento de um pensamento simbolizador, menos técnico e mais refletido, capaz de gerar produções noológicas, na concepção de Edgar Morin (1973). Tais artefatos sinalizam para aventura do sapiens-demens em suas construções sígnicas cujo objetivo é superar, ao menos nos registros imaginário e simbólico, sua condição de animal solitário, fadado a morrer sozinho, lembrando as palavras contundentes do filósofo e teórico da comunicação, Vilém Flusser (2007, p. 90-91):

1 Chamada MCTI/CNPq/MEC/CAPES n. 18/2012 - Ciências Humanas, Sociais, Sociais Aplicadas.

2 Grupo composto pelos professores doutores: Ana Guimarães, Heloísa Valente, Marco Bin, Michiko Okano; pela doutoranda, profa. Tatiana Amendola Sanches, pelos mestres: Davi de Sá, Gabriel Soares e Luiz Fukushiro e mestrandos: Penélope Lira, Vera Pasqualin e Wagner Alexandre da Silva. 
Cada um tem de morrer sozinho por si mesmo. E, potencialmente, cada hora é a hora da morte. Sem dúvida não é possível viver com esse conhecimento da solidão fundamental e sem sentido. A comunicação humana tece o véu do mundo codificado, o véu da arte, da ciência, da filosofia e da religião, ao redor de nós, e o tece com pontos cada vez mais apertados, para que esqueçamos nossa própria solidão e nossa morte, e também a morte daqueles que amamos.

A consciência de nossa primeira realidade física, mortal, impele a construção da cultura por meio da malha dos signos simbólicos. A urdidura do mundo codificado se faz também pela palavra, signo simbólico por excelência. Por sua vez, as narrativas primordiais, míticas e cosmogônicas, presentes em sociedades de tradição oral, desde as mais antigas formações humanas, revelam a arquipotência da Palavra, sua relação com a força mítica, com a esfera do sagrado, conforme lemos nos estudos de mitólogos, historiadores e filósofos da cultura, como Mircea Eliade (1985;1986), Jean Pierre-Vernant (1990) e Ernest Cassirer (1985) para quem existe um vínculo originário entre a consciência linguística e a mítico-religiosa: “em todas as cosmogonias míticas, por mais longe que remontemos em sua história, sempre volvemos a deparar com esta posição suprema da Palavra"(1985, p. 64).

Tentando definir a complexa realidade cultural que é um mito, Mircea Eliade (1986, p. 12), afirma: “o mito conta uma história sagrada, relata um acontecimento que teve lugar no tempo fabuloso dos 'começos'." A dimensão mítica da palavra que contamina os relatos e permite ao homem arcaico rememorar, pelo viés narrativo, e alcançar o tempo dos Seres Sobrenaturais, in nillo tempore, onde não existe morte, vale-se igualmente da eficácia sígnica da voz, ritualizada em diversas culturas, graças ao seu campo simbólico, capaz de operar a passagem do tempo cotidiano ao tempo mítico do começo absoluto.

Corpo-mídia em movimento, a voz e a narrativa mítica são capazes, nessas sociedades, de convocar a memória e revelar modos exemplares de existência, dos ritos às atividades cotidianas significativas: casamento, trabalho, educação, etc., para, sobretudo, dar sentido à vida e proporcionar o esquecimento momentâneo do misterioso tempo devorador e da morte que nos atravessam.

As singularidades das sociedades tradicionais em suas tentativas simbólicas de "curar o homem do sofrimento da existência do Tempo" (ELIADE, op. cit, p. 75), por intermédio das narrativas míticas e da memória, não se afastam das constatações de Flusser (2007) sobre os desígnios da comunicação humana e a constituição da cultura como uma segunda realidade ou semiosfera - universo dos signos na cultura, seguindo o semioticista de Tártu-Moscou, Iúri Lotman (1996). 
Em consequência, mesmo nas sociedades dessacralizadas e fragmentadas onde vivemos (em que constelações simbólicas são codificadas de modo diverso daquelas das sociedades em que o mito é uma realidade), podemos igualmente salientar o valor das narrativas geradas pelas vozes que acionam a memória individual, sempre articulada a uma memória coletiva, na intenção de vencer a angústia das perdas trazidas pela passagem inexorável do tempo.

\section{A memória narrada}

Ainda que o objetivo deste artigo não seja discutir os caminhos da memória ao longo das transformações culturais, vale dizer que a memória perde seus aspectos míticos e religiosos, rapidamente apontados acima, para adquirir um estado de laicização (VERNANT, 1990), ${ }^{3}$ especialmente relacionado ao surgimento da mnemotécnica, inventada pelos gregos.

Entre as numerosas artes que os gregos inventaram, a da memória permite a memorização graças a uma técnica denominada, por isso mesmo, de memória artificial, ou mnemotécnica. Frances Yates (1975), retomando o orador latino Caio Tulios Cícero (106 a.C. - 43 a.C.) que narra o mítico nascimento da mnemotécnica, esclarece que o poeta grego, Simônides de Céo, foi chamado para participar do banquete de um nobre da Tessália, Escopas, e deveria compor uma ode em homenagem ao anfitrião. Entretanto, em meio à ode, Simônides esquece o nome do nobre senhor e inclui, em seu lugar, uma passagem aos deuses Castor e Pólux, filhos de Júpiter. Ao final da apresentação, Escopas, bastante ressentido, nega fazer o pagamento, e diz ao poeta para que ele peça sua recompensa aos deuses. Neste momento, um servo chama por Simônides à porta do palácio, mas quando sai da casa, não há ninguém. A seguir, o palácio desmorona, soterrando Escopas e os demais presentes. O poeta foi capaz de identificá-los porque se lembrava do lugar em que os comensais estavam sentados, inaugurando, assim, os princípios da memória artificial: as lembranças das imagens, necessárias à memória, e um princípio de organização dessas imagens: os lugares.

A mnemotécnica serviu aos propósitos da retórica clássica. Os retores criavam palácios da memória, em suas mentes, para instalarem em cada nicho uma imagem que pudesse facilitar seus discursos, entrelaçando o trabalho com palavras e imagens. Mas é curioso perceber que a organização da memória artificial nasce também como elaboração da morte, pois é para nomear, ou seja, identificar os mortos sob os escombros do palácio

3 Para uma leitura mais completa sobre as relações entre os aspectos míticos da memória e suas transformações, consultar Nunes (2013a). 
de Escopas, que Simônides cria o sistema de lugares e imagens; a memória laicizada nasce, então, sob o signo do luto, no sentido freudiano de elaboração de perdas essenciais (FREUD, 1917).

Dizer o nome é operar a passagem do desconhecido à lembrança: "lembrar-se, em francês, se souvenir, significa um movimento de vir de baixo: sous-venir, vir à tona o que estava submerso" (BOSI, 1994, p. 46). Nomear e narrar é dar vida, trazendo à memória. E nesta medida, subverter a morte. Se este é nosso destino simbólico, urdido pelas palavras, imagens e memória, há certos momentos em que a necessidade de lembrar o passado para zerar a passagem do tempo e, de algum modo, ressignificar o tempo presente, se torna mais intensa.

Jay Winter (2006) identifica nos trabalhos de Pierre Nora, nas publicações produzidas entre 1984 e 1992, Les lieux de mémoire, um agente provocador e a inspiração para o que historiadores chamaram de "boom da memória e da história". Entre as tantas hipóteses para esta valorização em forma de trabalhos acadêmicos, comemorações, criações de museus e mega exposições, Winter (2006, p. 71) reconhece que a "geração da memória" sinaliza o fato de que "a criação e a disseminação de narrativas sobre o passado surgem e expressam políticas de identidade”. Do mesmo modo, Lígia Leite Pereira (2013, p. 116) corrobora esta ideia, imputando à velocidade da globalização, fortalecida nos anos 1990, a necessidade de recuperar "a constituição das identidades individuais e coletivas." E por conta deste debate, assiste-se a uma expansão dos projetos em História Oral.

Obviamente, esta expansão dialoga com o percurso da própria História como disciplina a medida que responde à trajetória de escolas de pensamento que valoraram novos procedimentos para pesquisar fontes para a reconstituição da História, a exemplo do grupo de Annales que, de 1929 a 1969, debateram com historiadores positivistas e historicistas. Mais tarde, este grupo passou a ser denominado como Nova História, “dedicando-se, sobretudo, à história do cotidiano e das mentalidades (...) A partir da ênfase dada ao estudo do cotidiano, os historiadores mostraram que as fontes da história não eram mais somente os documentos "oficiais"' (FREITAS, 2002, p. 45). O que se evidencia com o "boom da memória e da história", para a H.O, é o reconhecimento de fontes até então pouco prestigiadas.

Fontes orais, entrevistas, relatos, narrativas de histórias de vida ou histórias temáticas, histórias de famílias, as literaturas biográficas e testemunhais ganham terreno nas pesquisas em muitas áreas e também no mercado editorial. Os métodos da H.O se tornam decisivos em muitos projetos que pretendem discutir e contribuir para o fortalecimento das identidades locais. Paul Thompson (2002, p. 27) acredita que um dos desafios da H.O é, justamente, esclarecer o papel das identidades ao proferir que "um 
sentido de raízes, de identidade comum e de comunidade pode ser crucial para permitir a ação social local".

"A história oral tem um poder único de nos dar acesso às experiências daqueles que vivem às margens do poder, e cujas vozes estão ocultas porque suas vidas são muito menos prováveis de serem documentadas nos arquivos". (THOMPSON, op. cit, p. 17). Mulheres, velhos, minorias pouco representadas socialmente ou os que estão à margem completa, como criminosos e drogados, participam de esferas ocultas da sociedade que os procedimentos da H.O podem iluminar.

Na pesquisa que relato a seguir, construída seguindo alguns métodos da H.O, as vozes ocultadas são as de jovens. E, paradoxalmente, em uma era em que ser jovem é quase uma prerrogativa e uma imposição, jovens com preferências consideradas como diferentes podem também sofrer marginalização e ocultamentos. Ser escutado, falar de si, significa estar vivo. Pois, como já ensinaram os poetas da Grécia Arcaica, a Palavra participa do mesmo eixo paradigmático do Louvor, da Luz e de Mnemosyne, ou Memória. "As façanhas narradas pelos cantos dos poetas, na sociedade micênica, tornam a memória do guerreiro ilustre, isto é imortal" (NUNES, 2001, p. 40-41). O silêncio, o ocultamento diríamos, seguindo Thompson (op. cit.) - articulam-se ao esquecimento e à obscuridade: "as façanhas que são silenciadas morrem (...) somente a Palavra de um cantor permite escapar do Silêncio e da Morte" (DETIENNE, 1988, p. 20).

\section{Comunicação, consumo e memória: cosplay e culturas juvenis}

Ainda que o papel do pesquisador não seja o mesmo do poeta/aedo da Grécia Antiga, o pesquisador pode fazer falar narrativas silenciadas de muitos depoentes, reconhecendo a importância de suas experiências de vida, individuais, na reconstrução das vivências da coletividade. Fruto de um projeto que engloba onze pesquisadores, sob minha coordenação, a pesquisa "Comunicação, consumo e memória: cosplay e culturas juvenis", mencionada nas notas um e dois, nasceu do desconhecimento e do preconceito, funesta consequência da ignorância. Convidada para participar de um evento acadêmico cujo tema era cosplay, aproximei-me timidamente do objeto, consultando vídeos no YouTube. A primeira impressão foi a pior possível. Ocupando o lugar do pesquisador enclausurado em seu gabinete, menosprezei o que assisti, atribuindo àquelas cenas apenas a condição de meras reproduções de narrativas midiáticas massivas, sem qualquer aspecto criativo. Mas também fiquei intrigada.

Ainda naquele mesmo ano, tive nova oportunidade para desmanchar meus preconceitos e conhecer o cosplay e seus praticantes. Resolvi pensar em um projeto que 
pudesse investigar melhor o que tão logo chamaria de cena cosplay. A prática cosplay (do inglês costume play, roupas de brincar ou interpretar; fantasia) origina-se das feiras de filmes de ficção científica estadunidenses, em que os participantes, fantasiados como personagens dos filmes, realizavam desfiles. Esta prática chegou ao Japão durante os anos 1980 por meio de Nobuyuki Takahashi, após conhecer os concursos norte-americanos.

O jornalista publicou, em Tóquio, inúmeras matérias sobre o assunto denominando esta atividade como cosupurei - cosplay (NAPIER, 2013). Em 1978, no Japão, Mari Kotami realizou a primeira performance representando um personagem de mangá, os quadrinhos japoneses (LUNNING, 2011). Hoje os cosplayers japoneses transitam em áreas urbanas, não frequentam apenas as convenções de cultura pop, atravessam os bairros de Harajuku e Akihabara com trajes de toda ordem, não só performatizando personagens de mangás ou de animês (as animações para a tevê, vídeo e cinema), conforme relata Susan Napier (2013, p. 160): “ jovens mulheres vestidas como maids em preto e branco ou com a moda ligeiramente sexy conhecida como Rorigosu (Lolitas)".

Lolita é um gênero de moda urbana japonesa que expressa a estética kawaii, conhecida no Japão desde o século XII em Konjaku Monogatari (Antologia de Contos do Passado). Segundo a pesquisadora de arte oriental Michiko Okano (s/d), o kawaii (originalmente Kawayushi) significava ter pena, vontade de fechar os olhos diante de uma situação dolorosa. Na contemporaneidade o sentido se modificou, dizendo respeito a algo gracioso, mimoso, bonitinho, fofinho, que se correlaciona a coisas pequenas, delicadas, frágeis, que precisam ser cuidadas. A moda Lolita responde à cultura do Japão soft e, na pesquisa relatada, insere-se na cena cosplay.

Em nosso país o cosplay e o estilo Lolita alcançam os centros urbanos no final dos anos 1990, juntamente com as convenções de mangás e animês que, por sua vez, chegaram ao Ocidente antes dos mangás, já na década de sessenta (NAGADO, 2005). Em face da historiografia do cosplay, ainda incompleta, a pesquisa procura responder o seguinte problema: como os fãs/jovens habitam e consomem as memórias dos filmes, games ou outros textos culturais que tenham gerado o desejo pelo cosplay, e de que forma a cena cosplay garante sua própria memória e permanência na cultura juvenil? Se há alguma permanência nesta prática ou cena, ela pode vir a constituir uma comunidade? Qual seriam seus modos de vinculação?

Para tanto, foram observados: a qualidade ou característica dos laços estabelecidos entre o cosplayer e seu personagem de afeto; as características das vinculações entre os membros deste coletivo; os modos de produção e os processos de construção de memória e de vínculos, as dinâmicas de transmissão e circulação dos textos culturais envolvidos; como o consumo de narrativas, personagens e discursos midiáticos podem 
significar o cotidiano das culturas juvenis, construindo identidades, diferenças, identificações, relações sociais e políticas. Apenas seria viável perceber estas relações mediante uma cartografia da cena cosplay que conseguisse construir uma representação significativa. Por isso, foram cartografados dez eventos na capital de São Paulo e três nas cidades de Rio de Janeiro, Belo Horizonte e Vitória por meio da pesquisa de campo.

O objetivo geral da pesquisa é verificar quais as lógicas e estratégias da produção da cena cosplay na região Sudeste em eventos de animes, tanto os organizados por grandes empresas como eventos elaborados exclusivamente por fãs, cartografando regularidades e singularidades por meio da análise das formas de transmissão, circulação, consumo e memória de narrativas (mangás, animês, games ou outros gêneros que tenham gerado o desejo pelo cosplay), analisando também a importância da música e da moda urbana japonesa já hibridizada a outros signos da cultura pop para a configuração desta cena.

Neste trabalho observo apenas a presença dos métodos da História Oral na realização do trabalho de campo, sem apresentar os resultados finais da pesquisa que, posteriormente, estarão disponíveis em formato de um livro.

\section{História temática e histórias de vida}

A pesquisa, multimetodológica, abriga a pesquisa de campo e a bibliográfica, pois cada subprojeto, percorrendo um objetivo específico e desenvolvido por cada um dos pesquisadores, seguiu um trajeto metodológico diverso. No subprojeto que desenvolvi especialmente voltado para a comparação entre as capitais do sudeste brasileiro, alguns métodos da História Oral foram sistematicamente aplicados no campo: a partir de um roteiro aberto, procurou-se abordar uma história temática (FREITAS, 2002) direcionada aos desdobramentos da cultura pop. As perguntas aos depoentes referem-se a três eixos. O primeiro deles contempla o tema da cultura pop japonesa, enfatizando a iniciação de cada um dos cosplayers na cultura cosplay, o que permitiu que os jovens trouxessem à baila o motivo de realizarem tal prática, e, do mesmo modo, o que isto representava em suas vidas. O exemplo de Kimi, jovem que se nomeia pelo codinome de sonoridade oriental, é bastante ilustrativo. ${ }^{4}$

Cosplayer e "animekeira", isto é, cantora de trilhas sonoras de animês, conta que aos dez anos de idade já era leitora de mangás. Sua mãe matriculou-a em uma escola de japonês e, desde então, não mais parou de estudar esta língua. Em 2012, ano em que realizei a entrevista, Kimi era professora de inglês e mestranda em Linguística Aplicada na Pontifícia Universidade

4 O exemplo de Kimi está também narrado em outra publicação de minha autoria (NUNES, 2012, p. 86-87). A jovem foi entrevistada no Anime Party 2012. Faculdades Cantareira, São Paulo, SP. 
Católica de São Paulo. Pergunto de que modo transfere sua experiência de "animekeira" e de cosplayer para sua vida fora dos eventos. Ao responder, revela também seu desejo:

eu gosto muito de idiomas, dou aula de inglês e tento transferir pros meus alunos a importância de se falar uma outra língua [...] um idioma não é só um idioma, ele é cultura [...] se você aprende japonês, aprende a cultura japonesa [...] eu tô me esforçando pra pegar uma turma de japonês, seria a minha primeira, mas é difícil passar credibilidade, ainda se tem a imagem de que um professor de japonês tem que ser japonês [...].

Kimi relata também que "gostava dos animês desde pequena [...] as letras têm sempre uma mensagem de amizade, de superação, de não abrir mão dos seus sonhos". Percebe-se que a leitura do mangá - texto cultural, no sentido de Lotman (1996) - experimentada na infância participa em variados níveis da vivência contextual desta jovem: aprender idiomas, gostar de cantar trilhas de animês. As conexões entre memórias autobiográficas e memórias e identidades coletivas, como a prática cosplay - atividade compartida que serve à sociabilidade e ao pertencimento a uma cena - foram regularmente observadas nos relatos.

Fazer cosplay refere-se, em muitos depoimentos, sobretudo dos jovens adultos, à preferência pelos animês, a exemplo de Cavaleiros do Zodíaco, transmitido pela extinta tevê Manchete. Narrar que assistiam à tevê remete igualmente à intimidade da casa, à presença de irmãos, primos, familiares. Curiosamente, os mais jovens condicionam sua iniciação ao mundo cosplay pelo viés da internet, o que nos indica o papel das mídias na vida destes sujeitos, alterando as formas de transmissão, circulação e consumo das narrativas midiáticas que servem de inspiração para os cosplayers, assim como foi possível, com base na história temática, reconhecer a história da mídia tecida nas histórias de vidas reportadas.

O segundo eixo temático diz respeito aos personagens e às narrativas selecionadas para composição dos cosplays. Os modos de lembrar e os de consumir estes textos culturais mostram-se igualmente articulados às histórias de vida destes sujeitos. Iuri Lotman e Bóris Uspenskii (1981, p. 43-44) consideram três maneiras específicas para dar conteúdo à cultura comportando-se como memória longeva da coletividade: o aumento quantitativo do volume dos textos que compõem a cultura, a redistribuição do fato memorizável, isto é, sua valorização hierárquica na cultura e reorganização ininterrupta do sistema codificador, que torna possível o aumento da memória graças “a criações de reservas inatuais, mas capazes de adquirirem atualidade", e, finalmente, o esquecimento, que se apresenta como um processo seletivo, acionando certos textos e abandonando outros, pois, "qualquer texto contribui não só para a memorização, mas também para o esquecimento." 
A pesquisa pode então se valer destes três procedimentos para responder aos modos de lembrar. A questão básica se relacionava ao modo de seleção envolvido no ato de escolher determinado personagem para fazer o cosplay em face de uma vasta rede de personagens e enredos disponíveis. Não raro, a narrativa selecionada revelou a presença de certos textos midiáticos na cultura, certos animês, games, HQs muitas vezes considerados como narrativas ou personagens em alta, "bombando", o que nos aproxima da ideia sobre volume de textos para conferir conteúdo à memória, seguindo os pensadores de Tártu-Moscou. Porém, a pesquisa também revelou singularidades, como o exemplo de uma jovem que só escolhia personagens para representar que tivessem cabelos pretos como os dela porque sua família, bastante contrária àquela prática, não permitia que ela gastasse dinheiro com perucas ou com muitos acessórios.

A singularidade desta escolha destaca os traços da história familiar da cosplayer, as prescrições e os limites impostos na composição das personagens lembradas para fazer o cosplay. Do mesmo modo, essa escolha conduzida por motivações tão particulares permite demonstrar que a cena cosplay convoca a memória midiática, tendo em vista todas as narrativas e personagens possíveis de serem materializadas por meio dos indumentos durante os eventos, mobilizando o sistema codificador da cultura que redistribui a presença e a hierarquia de narrativas e personagens acionados pela memória individual, nem sempre os mais célebres, evidenciando o jogo constante entre as memórias individuais e coletivas.

Dessa questão decorre o terceiro eixo a ser pesquisado: os modos de consumir e fazer o cosplay para apontar as junções entre o consumo midiático, observado pela escolha do personagem, o consumo material, ou seja, os materiais disponíveis e usados para produzir o cosplay (já que a tônica desta prática é o cosplayer costurar o próprio traje, senão completamente, pelo menos parte dele, ou elaborar os acessórios que o compõe como armas, espadas, etc.) e o consumo simbólico-afetivo, verificando de que maneira a seleção de personagens e os modos de construí-los significam e criam identificações, identidades, diferenças e relações políticas. Acreditamos, como Mike Featherstone (1995), que a simbolização e o consumo de bens materiais são comunicadores, não apenas utilidades.

Com regularidade, os cosplayers fazem cosplays de personagens diversos ao longo das convenções que frequentam, seguindo inúmeras motivações: o afeto ou "identificação" com a personagem; similaridade física, como a jovem citada acima; o tamanho do evento, pois em convenções muito grandes e cheias fica difícil caminhar pelo local do encontro com cosplays muito elaborados; o clima. Saliento, entretanto, a entrevista de José Luiz, publicitário paulista, que narrou que faz cosplay unicamente do personagem Jedi Mace Winu, da segunda trilogia de Stars Wars. José Luiz assume uma postura 
política, pois seleciona seu personagem pela representatividade que exerce socialmente. Afirma que no Brasil a questão do racismo é forte e que, por isso, escolhe um personagem negro pra ficar marcado. O publicitário reporta: "tu olha aqui, é o único Jedi que tem (...) as pessoas afrodescendentes não têm uma referência, e quando têm uma referência, se alegram em ver, principalmente criança." ${ }^{\prime}$ Mais uma vez, as relações entre a história de vida, temática e midiática se conjugam no exercício desta prática de sociabilidade e de significação.

Essas questões e suas respectivas respostas conduziram os relatos e, ao deixarem falar suas memórias, os cosplayers fizeram surgir novos temas e problematizações que não estavam presentes no escopo inicial da pesquisa, tal como o preconceito que sofrem. O jovem Iuri, vindo de Macapá para desfilar no concurso de cosplays do Anime Dreams 2013, sugeriu que a questão do preconceito fosse incorporada à pesquisa, pois é bastante comum que o cosplayer sofra discriminações entre os amigos da escola ou do trabalho e, não raro, da própria família. Outro flanco temático se abriu. Do mesmo modo, a discussão sobre as representações sociais dos negros nesta cena jovem em que grande parte dos personagens a serem representados é branca descolou-se do depoimento de José Luiz e permitiu reconhecer dimensões políticas neste entretenimento. Ainda que a prática cosplay seja compreendida, de modo geral, como lazer, o consumo e a memória de personagens indicam investimentos e representações identitárias plasmadas no desejo de resistência e transformação social, muitas vezes. Por outro lado, as identidades construídas pelo viés da fantasia e da ficção também revelaram desigualdades sociais e culturais.

\section{O flâneur e o pesquisador em uma cena lúdica: o protocolo e suas rupturas}

Compreendendo a História Oral como Thompson (op. cit), que entende a interpretação da história, das sociedades e culturas por meio da escuta das pessoas e do registro de suas experiências e lembranças, esta pesquisa escutou vozes de jovens, e talvez seja pertinente dizer que eles não estão agrupados em uma categoria biológica. A prática cosplay configura-se como uma cena jovem, ainda que possam ser encontrados cosplayers de 40 anos, como José Luiz, citado acima, graças ao espírito lúdico e à brincadeira que permanecem como traço indelével das culturas e, de modo particular, se presentificam em personagens que pertenceram à infância de muitos dos entrevistados.

5 José Luiz foi entrevistado no Anime Friends 2013. Campo de Marte, São Paulo, SP, julho de 2013. Este exemplo também se encontra relatado em outros artigos que apresentaram os resultados parciais da pesquisa.

$102 \frac{\text { Comunicação \& Inovação, PPGCOM/USCS }}{\text { v. 16, n. } 30 \text { (91-106) jan-abr } 2015}$ 
De outro modo, verificam-se aqui as "dilatações juvenis", nas palavras de Canevacci (2005, p. 29), designadas para reconhecer que, em nossos tempos, "cada indivíduo pode perceber sua condição de jovem como não-terminada e, inclusive, como não-terminável". Ainda que o público, especialmente dos eventos, gire em torno de $15 \mathrm{a}$ 25 anos, é bastante comum encontrarmos jovens adultos, pais e filhos vestidos como seus personagens de afeto ou senão, no caso de pais, portando algum acessório da personagem. Os jovens não vivem suas juventudes da mesma maneira, suas narrativas e suas memórias puderam demonstrar isso: diferenças de renda, de formação familiar, de projetos de vida apareceram durante a pesquisa.

Seguindo os passos de Peter McLaren (2000), professor de Educação da Universidade da California, Los Angeles (que acredita que o etnógrafo possa ser como o flâneur descrito por Edgar Alan Poe, Charles Baudelaire e Walter Benjamin), fui a campo conduzida por um roteiro básico, mas não fechado, de modo a evidenciar a flânerie, como já descrevi em outro artigo (NUNES, 2013, p. 4-5):

\begin{abstract}
A flânerie se tornou guia - modo de potencializar a ambiência da cena: caminhar lentamente pelo lugar, conhecer os espaços e as atrações, sentir seus sons, seus aromas, contaminar-me pelas cores das vestes, perucas e lentes, depois, amorosamente, acercar-me dos jovens, interrompendo o fluxo de seus passos, tomada por forças casuais, sensóreas, estéticas. (...) Não há estranhamentos na cena cosplay: não me visto como um personagem, sou bem mais velha do que muitos ali, carrego máquina de vídeo, pasta, caderno, caneta e nem mesmo possuo qualquer identificação que possa me marcar como uma de fora. Sem qualquer constrangimento, entregam seu tempo ao meu desejo de capturar os interstícios desta prática.
\end{abstract}

Mergulhada nesta cena em que corpos excessivamente coloridos desfilam em meio a um espaço lúdico, de música em alto volume, sou levada a dialogar com os cosplayers. E muito diferente dos protocolos estabelecidos pelos procedimentos admitidos para uma entrevista, como "não interferir na fala e nunca fazer nenhum juízo de valor" (FREITAS, 2002, p. 94), sou levada à admiração e, não raro, faço comentários elogiosos à forma como realizaram o cosplay. Surpreendo-me pelas habilidades demonstradas com a costura dos trajes, com a criatividade dos acessórios, dou risadas junto com eles quando me contam algum episódio do animê que foram decisivos em suas vidas. E me pergunto como poderia escutá-los, adquirir a confiança necessária para que narrassem suas experiências com o universo cosplay, tantas vezes atravessadas por suas histórias de vida, sem que eu também estivesse ali como sujeito. Talvez redimindo o preconceito inicial e confessando meu encantamento. 


\section{Considerações Finais}

Este artigo procura demonstrar as conexões entre as Ciências da Comunicação e as Ciências da Cultura, evidenciando a trajetória simbólica da palavra inserida em processos narrativos fundamentais para a compreensão da memória - tanto em sua dimensão cultural como individual, sempre entrelaçadas, facilitando o entendimento da memória como matéria da História Oral.

Como objeto de relato, apresento a pesquisa "Comunicação, consumo e memória: cosplay e culturas juvenis", realizada sob minha coordenação, inspirada em alguns dos procedimentos metodológicos da História Oral como a escuta de depoimentos dos participantes da cena cosplay. Esta escuta permitiu incorporar à pesquisa questões surgidas das próprias falas dos cosplayers, que modificaram a direção inicial do trabalho, introduzindo questionamentos inimagináveis antes da escuta. De outro modo, dar voz aos cosplayers permitiu identificar os engendramentos entre a memória midiática e as experiências vividas pelos entrevistados por meio de um roteiro que visava uma história temática apoiada em seus relatos de vida, partindo da iniciação de cada cosplayer à cena cosplay.

O uso dos procedimentos da História Oral foi também acoplado ao conceito de flânerie como método, permitindo uma aproximação e, simultaneamente, um afastamento do objeto de pesquisa. Esta conjugação em meio a uma cena jovem performativa, marcada pela expressividade, de certo modo, tornou possível o cumprimento de certos protocolos relativos a tomada de depoimentos, mas também instalou rupturas marcadas sobretudo pela presença do pesquisador junto à cena e aos relatos coletados como sujeito em interação.

\section{Referências}

BAITELlO JUNIOR, N. A serpente, a maçã e o holograma. São Paulo: Paulus, 2010.

BOSI, Ecléa. Memória e Sociedade. São Paulo: Companhia das Letras, 1994.

CANEVACCI, M. Culturas Extremas: Mutações Juvenis nos Corpos das Metrópoles. Rio de Janeiro: DP\&A, 2005.

CASSIRER, Ernest. Linguagem e mito. Tradução J. Guinsburg e Mirian Schnaiderman. São Paulo: Perspectiva, 1985.

ELIADE, M. O mito do eterno retorno. Tradução Manuela Torres. Lisboa: Edições 70, 1985. . Aspectos do Mito. Tradução Manuela Torres. Lisboa: Edições 70, 1986.

FEATHERSTONE, Mike. Cultura de consumo e pós-modernismo. São Paulo: Nobel, 1995.

FLUSSER, V. O mundo codificado. São Paulo: Cosac Naify, 2007.

$104 \frac{\text { Comunicação \& Inovação, PPGCOM/USCS }}{\text { v. 16, n. } 30 \text { (91-106) jan-abr } 2015}$ 
FREITAS, S. História Oral: possibilidades e procedimentos. São Paulo: Imprensa Oficial, 2002.

FREUD, S. Luto e melancolia. In: Metapsicologia. Rio de Janeiro: Imago, 1974.

LANG, A. B.S. G. Trilhas da pesquisa, convicções e diversidades. In: SANTHIAGO, R. ; MAGALHÃES, V. Depois da utopia: a história oral em seu tempo. São Paulo: Letra e Voz/Fapesp, 2013.

LEROI-GOURHAN, A. O gesto e a palavra. Lisboa: Edições 70, 1985. (v. 1)

LOTMAN, Y. Acerca de la Semiosfera. In: La Semiosfera I. Madri: Ediciones Cátedra, 1996.

; USPENSKII, B. Sobre o Mecanismo Semiótico da Cultura. In: Ensaios de Semiótica Soviética. Lisboa: Livros Horizontes, 1981.

LUNNING, F. Cosplay, Drag, and the performance of abjection. In: PERPER, T.; CORNOG, M. (Ed). Mangatopia. Santa Barbara, California: Libraries unlimited, 2011.

MCLAREN, P. Multiculturalismo Revolucionário. Porto Alegre: Artmed, 2000.

MORIN, Edgar. O Paradigma Perdido. Trad. Hermano Neves. Lisboa: Publicações Europa-America, 1973. NAGADO, A. O Mangá no Contexto da Cultura Pop Japonesa e Universal. In: LUYTEN, S. (Org.) Cultura Pop Japonesa. São Paulo: Hedra, 2005.

NAPIER, S. From impressionismo to anime: Japan as fantasy and fan cult in the mind of the West. New York: Palgrave MacMillan, 2013.

NUNES, M. R. F. A memória na mídia: a evolução dos memes de afeto. São Paulo: Annablume/FAPESP, 2001.

Mito, memória e comunicação: da tradição oral à oralidade mediatizada. In: SANTHIAGO, R. e MAGALHÃES, V. (Org.). Depois da utopia: a história oral em seu tempo. São Paulo: Letra e Voz/ Fapesp, 2013.

Quem não cresceu assistindo Dragon Ball? Consumo, memória e juventudes na cena cosplay. Trabalho apresentado no Grupo de Trabalho 09, Comunicação, Consumo e Memória, do $3^{\circ}$ Encontro de GTs - Comunicon, realizado nos dias 10 e 11 de outubro de 2013. ESPM, São Paulo. Consumo musical nas culturas juvenis: cosplay, mundo pop e memória. Revista Contracampo, Niterói, n. 25, p. 80-96, dez 2012.

OKANO, M. A imagem do Japão. Disponível em: <http://www.academia.edu/3840267/A_imagem_do_ Japao_contemporaneo $>$. Acesso em maio de 2014.

PEREIRA, L. Trajetórias e desafios no percurso da história oral brasileira. In: SANTHIAGO, R. e MAGALHÃES, V. (Org.) Depois da utopia: a história oral em seu tempo. São Paulo: Letra e Voz/ Fapesp, 2013.

THOMPSON, P. História oral e contemporaneidade. História Oral, Paraná, v. 5, p. 9-28, 2002. Disponível em: < http://revista.historiaoral.org.br/index.php?journal=rho\&page=article\&op=view\&path\%5B \%5D=47\&path\%5B\%5D=39>. Acesso em: 15 mai. 2014.

VERNANT, Jean-Pierre. Mito e Pensamento entre os Gregos. Tradução Haiganuch Sarian. Rio de Janeiro: Paz e Terra, 1990. 
WINTER, J. A geração da memória: reflexões sobre o "boom da memória" nos estudos contemporâneos de história. In: SELIGMMAN SILVA, M. (Org). Palavra e imagem: memória e escritura. Chapecó: Argos, 2006.

YATES, Frances. L'art de la mémoire. Traduit de l'anglais par Daniel Arasse. Paris: Gallimard, 1975. 